\title{
CFD Study of a Variable Flow Geometry Radial Ejector
}

\author{
Hadi Rahimi, David Buttsworth, Ray Malpress \\ School of Mechanical and Electrical Engineering, University of Southern Queensland \\ Queensland 4350, Australia \\ hadi.rahimi@usq.edu.au; David.Buttsworth@usq.edu.au; Ray.Malpress@usq.edu.au
}

\begin{abstract}
To achieve higher performance from ejectors at some working conditions, implementations of variable geometry might be possible. While axisymmetric ejectors with axial flow paths have limitations that make practical implementation of variable geometry difficult, radial ejector configurations have a flow path that is conducive to changes in nozzle and ejector throat area during operation. The geometric adjustment of the radial ejector could be made by simply changing the separation of the radial ejector duct walls and/or the separation of the nozzle walls in order to optimize performance over a range of different conditions. The effects of such changes on the performance of a radial ejector have been investigated using a Computational Fluid Dynamic (CFD) analysis with ANSYS FLUENT software. Axisymmetric CFD models were generated to assess performance for a primary nozzle throat area of $8.792 \mathrm{~mm}^{2}$ and for ejector throat separations of $2.2 \mathrm{~mm}, 2.4 \mathrm{~mm}$ and $3.0 \mathrm{~mm}$, corresponding to ejector throat areas of $497,543 \mathrm{and} 678 \mathrm{~mm}^{2}$, respectively. The CFD analysis reveals that changes ejector performance can be achieved by changing the ejector duct's separation. An increase of $34 \%$ in entrainment ratio can be achieved by increasing the ejector throat separation from $2.2 \mathrm{~mm}$ to $3.0 \mathrm{~mm}$ at fixed primary and secondary pressures of $160 \mathrm{kPa}$ and $1.8 \mathrm{kPa}$, respectively. If an increase in the ejector malfunction pressure is needed, it could be achieved by decreasing the ejector duct separation. An overall malfunction pressure increase of $18 \%$ can be achieved by decreasing the ejector throat separation from $3.0 \mathrm{~mm}$ to $2.2 \mathrm{~mm}$ at primary and secondary pressures of 250 and $1.8 \mathrm{kPa}$, respectively.
\end{abstract}

Keywords: Radial ejector, air ejector, variable geometry, supersonic radial nozzle

\section{Introduction}

Different approaches have been employed in order to improve ejector performance as characterised by the entrainment ratio and the compression ratio [1], [2]. Variable geometry [3], [4], [5], and oscillatory motive pressure [6], [7] , [8] are known methods that can affect ejector performance. A rotary radial ejector was introduced by [9], [10] and positive effects from the oscillatory behaviour in the primary flow were obtained though concepts were not ultimately successful because of mechanical failure from the very high rotary speeds [9].

While traditional ejectors employ an axisymmetric and axial flow path, a radial ejector is a viable configuration for convenient geometry change during the ejector operation. Fig. 1 presents general arrangements showing the flow paths of axial and radial ejectors. In the radial configuration, the primary flow expands in a supersonic radial flow nozzle, and this expanding disk of primary flow entrains the secondary flow. The secondary inlets have been positioned on either side of the expanding primary flow. This radial ejector configuration does not require moving components to achieve the entrainment and compression effects, and has been investigated via CFD simulation [11]. 


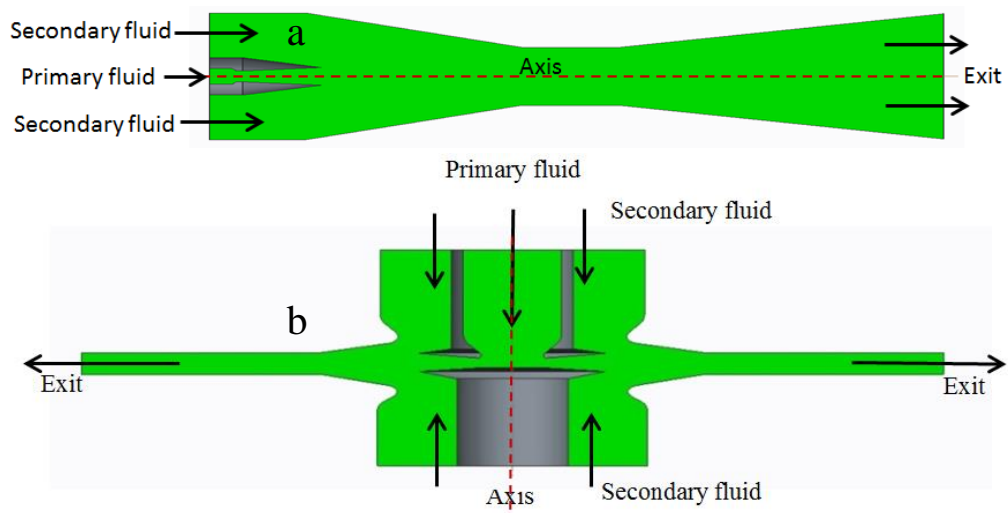

Fig. 1: Illustration of a: axial and b: radial ejector flow paths [11].

It is well established that adjusting the position of the supersonic nozzle exit plane in an axial flow path ejector can affect the ejector entrainment ratio. The influence of changes in the primary nozzle throat area in an axial flow path ejector has been also studied in the literature [12]. However, the axial ejector's form restricts the practical application of variable geometry concepts and the new radial configuration could be a solution to achieve variable geometry in the ejector at different operating conditions. The new radial ejector configuration does not have rotary parts and offers a convenient approach for altering the ejector flow area by changing the separation of the plates that form the walls of the ejector duct.

Computational Fluid Dynamics (CFD) has been extensively employed in literature to simulate ejector performance and flow characteristics. Most CFD ejector models have been validated by comparing with experimental data [13], [14], [15] with most authors claiming acceptable agreement with experimental results [16]. In some of these studies, simulations have been within $10 \%$ of the experimental data [4], but errors around $20 \%$ have been reported in [4]. Although the absolute reliability of CFD simulations remains uncertain, computational simulations using ANSYS Fluent should be sufficiently reliable to define, at least approximately, the sensitivity of ejector performance to variations in the ejector geometry.

Although the radial configuration of [11] was introduced as a simple approach to achieve geometric variability in the ejector, no analysis has yet been reported to demonstrate the effectiveness of the concept. This paper presents CFD simulations that quantify the sensitivity of radial flow ejector performance to geometry variations that can be achieved by altering the separation of the plates that form the walls of the ejector duct.

\section{Methodology}

The design of a radial ejector by adapting axial flow ejector design methods [17], [18] to suit the radial configuration was presented in [11]. The radial ejector described in [11] forms the basis for the present work. The primary nozzle has a throat area of $8.792 \mathrm{~mm}^{2}$, exit area of $179 \mathrm{~mm}^{2}$, nozzle area ratio of 20 , nozzle divergent part length of $9.5 \mathrm{~mm}$ and divergent half angle of $5^{\circ}$. Fig. 2 provides a schematic illustration the ejector primary nozzle and the plates that form the ejector duct showing the separation of the ducts $(\mathrm{h})$. The separation is the minimum distance between the upper and lower ejector plates. By changing the separation, the ejector area is changed. 


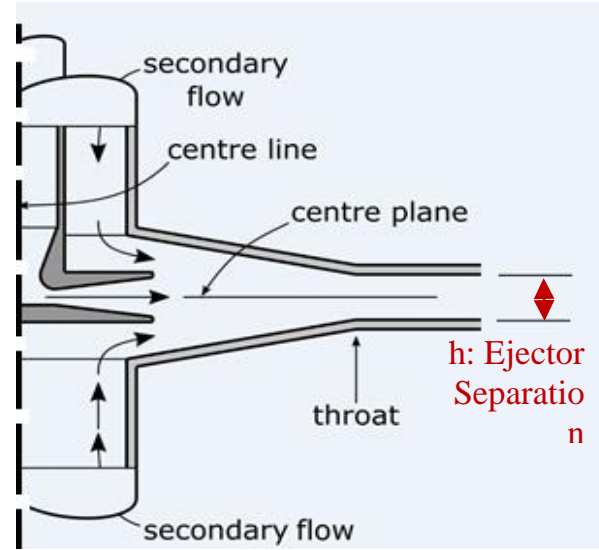

Fig. 2: The radial ejector duct showing the radial ejector duct separation.

Fig. 3 shows the radial ejector areas for ejector duct separations of 2.2, 2.4 and $3.0 \mathrm{~mm}$. The ejector throat areas for separation of 2.2, 2.4 and $3 \mathrm{~mm}$ are 497,543 and $678 \mathrm{~mm}^{2}$ respectively and the corresponding ejector area ratios are 56.5, 61.8 and 77.

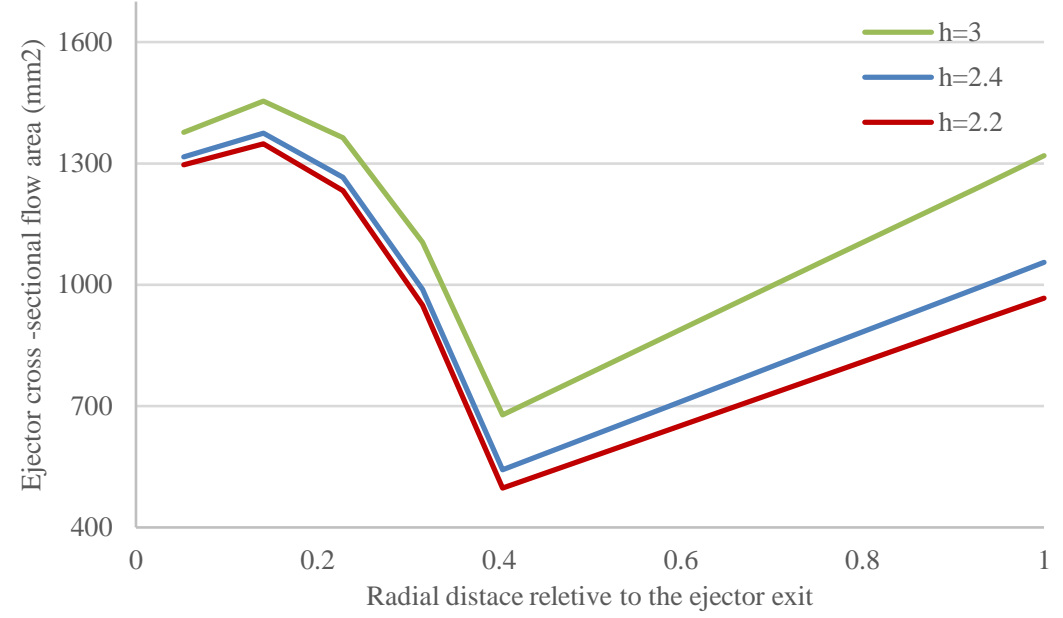

Fig. 3: Variation of the radial ejector cross-sectional flow area along the ejector radius relative to the ejector exit radius.

Three axisymmetric (two dimensional) CFD models were created for this study and ANSYS FLUENT 14.5 was used for the simulations. A mesh independence analysis was performed for the model in previous work [11] and based on those results, the total number of elements chosen for the simulations in this study were 51451, 53126 and 59324 for 2.2, 2.4 and $3.0 \mathrm{~mm}$ throat separations respectively. The details of mesh independence analysing and validation strategy has been reported in [11].

The working fluid for the simulations was air which was treated as an ideal gas. The primary and secondary inlets were set as 'pressure-inlet' and the ejector exit was set as a 'pressure-outlet'. Primary pressures of 160, 200 and $250 \mathrm{kPa}$ were selected for the motive fluid conditions and the secondary pressures of 1.8, 2.5 and $3.2 \mathrm{kPa}$ were used for the secondary inlet condition. Different outlet pressures ranging from 2 to $7 \mathrm{kPa}$ were applied. The $\mathrm{k}-\omega \mathrm{SST}$ turbulence model has shown consistent results in other ejector simulations [2] and has been used in this study as well.

The density-based implicit solver, which has been verified as a suitable solver for supersonic flow fields [19], [20], has been employed in this study. A second order upwind scheme was selected to discretise the equations to achieve higher accuracy at cell faces [21]. To define convergence of the solution, all residuals for calculations must fall to a specific level [20], which, for the present work was specified as less than $10^{-5}$. Essentially the same CFD modelling has been used for the three different geometries - different separations of the plates that form the ejector duct in the present work: the choice of solver, the turbulence model, the working fluid, the boundary conditions and convergence criteria were the same for 
both studies. Therefore, it is expected that simulation results from the three different ejectors will reflect the real flow with similar accuracy to that achieved with the previous study [11].

\section{Results and Discussion}

Fig. 4 shows the Mach number contours for the three separations of 2.2, 2.4 and $3.0 \mathrm{~mm}$ at the primary pressure of 160 $\mathrm{kPa}$, secondary pressure of $1.8 \mathrm{kPa}$ and exit pressure of $2.5 \mathrm{kPa}$. For all three cases, the expected flow features - such as sonic velocity at the primary nozzle throat and supersonic flow in the divergent part - have been obtain by CFD simulations.

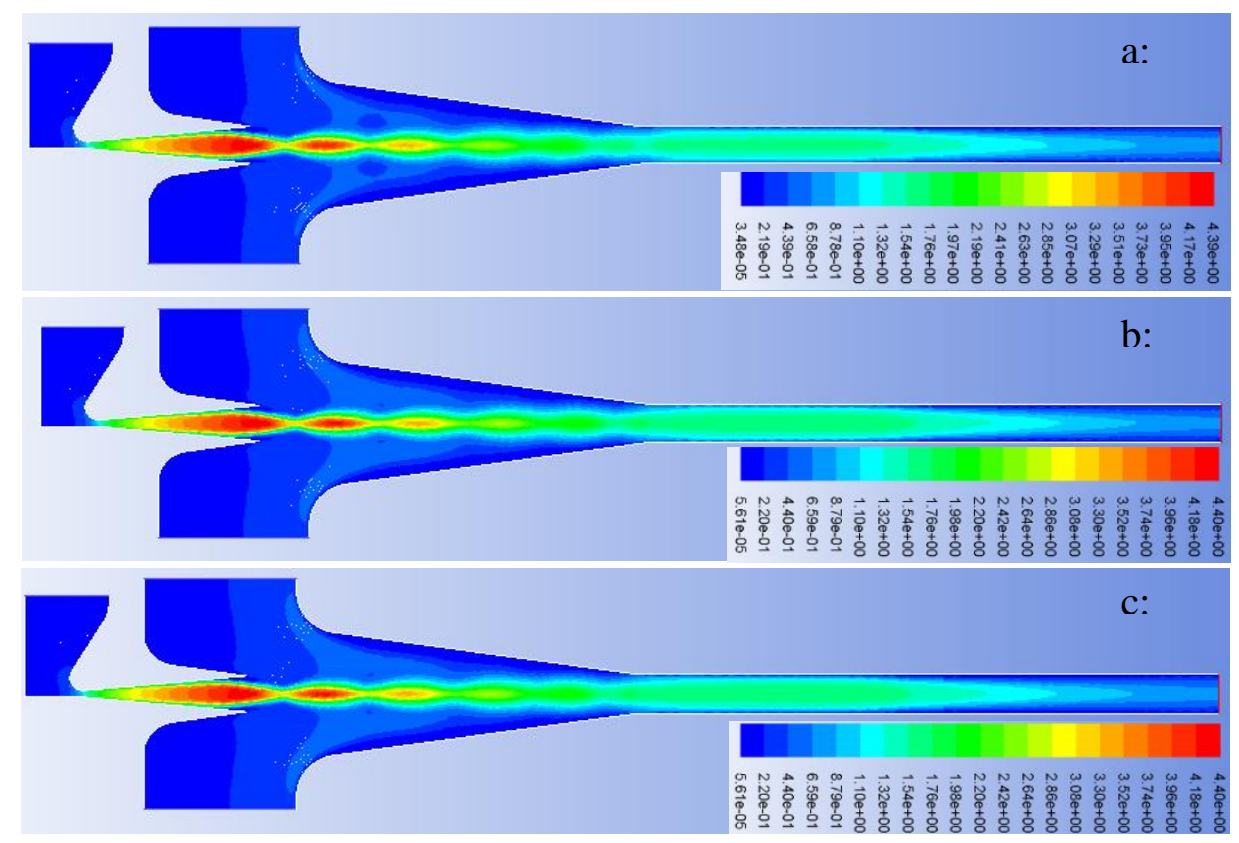

Fig. 4: Contours of Mach number for primary pressure of $160 \mathrm{kPa}$, secondary pressure of $1.8 \mathrm{kPa}$ and exit pressure of $2.5 \mathrm{kPa}$ for minimum plate separations of (a) $2.2 \mathrm{~mm}$; (b) $2.4 \mathrm{~mm}$; and (c) $3.0 \mathrm{~mm}$.

The effects of exit pressure have been evaluated using CFD for the primary and secondary pressure of $160 \mathrm{kPa}$ and 1.8 $\mathrm{kPa}$ respectively and different ejector exit pressure values from 1.8 to $5 \mathrm{kPa}$. The ejector performance in terms of entrainment ratio (ER) is presented in Fig. 5 for separations of 2.2, 2.4 and $3.0 \mathrm{~mm}$. At this working condition, the maximum entrainment ratio of 0.82 was obtained for a separation of $3.0 \mathrm{~mm}$. Entrainment ratios of 0.67 and 0.61 were obtained for separations of 2.4 and $2.2 \mathrm{~mm}$ respectively. By analogy to axial flow ejector cases such as discussed in [20], an explanation for this effect is that a larger effective secondary flow area is available for larger plate separations.

The critical pressure (where the entrainment ratio starts to decrease) and the malfunction pressure (where the entrainment ratio drops to zero) are also affected by the duct separations. The lowest malfunction pressure occurred for a plate separation of $3 \mathrm{~mm}$ for this working condition. The malfunction pressure was increased by about $7 \%$ when the separation was decreased to $2.4 \mathrm{~mm}$, but further reductions in the plate separation did not yield a significant change in the malfunction pressure. It was shown that the total length of the ejector plays an important role in the critical and malfunction pressures [17], [22], [23]. The total length of all three ejector duct separations are the same in the present work. This change in the malfunction pressure reflects the effects of ejector duct separation on the malfunction pressure. 


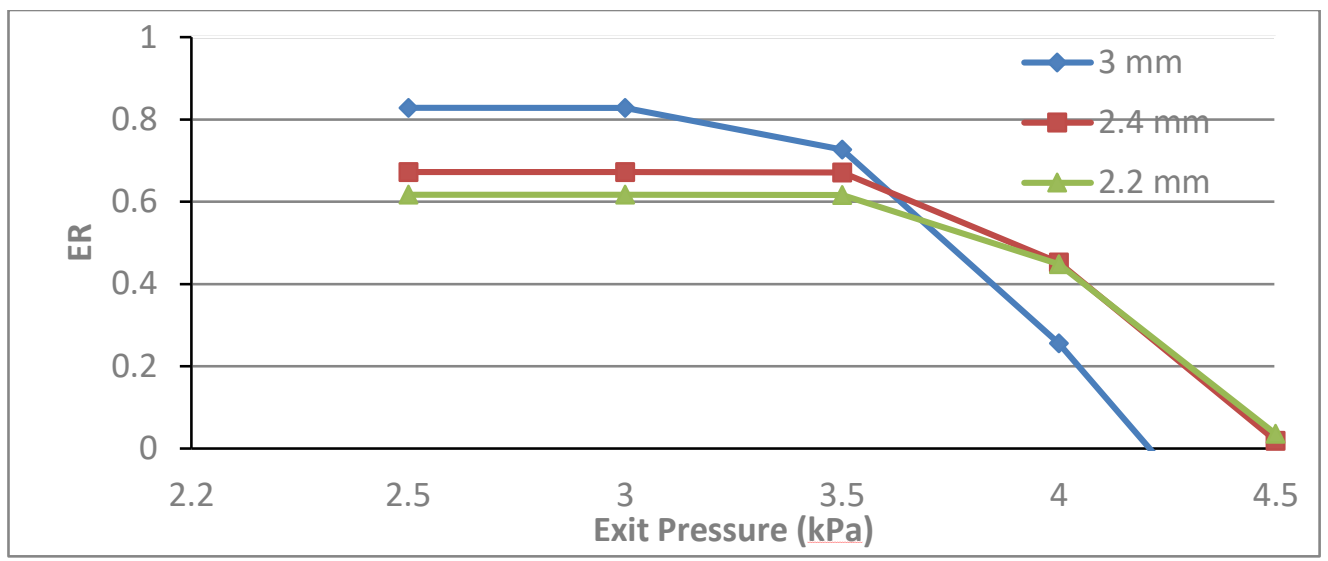

Fig. 5: Characteristic curves for radial ejector for 2.2, 2.4 and $3 \mathrm{~mm}$ separations at primary and secondary pressures of 160 and $1.8 \mathrm{kPa}$ respectively.

Fig. 6 presents the contours of Mach number for the exit pressure of $4.5 \mathrm{kPa}$. By comparing contours of Mach numbers for exit pressures of $4.5 \mathrm{kPa}$ (Fig. 4) and $2.5 \mathrm{kPa}$ (Fig. 6), it is observed that increasing the exit pressure moves the position of the shock structures upstream. This effect is also reported elsewhere [11], [19], [20], [19]. Fig. 6 show that for $3 \mathrm{~mm}$ separation, unbalanced flow in the ejector occurs with an exit pressure of $4.5 \mathrm{kPa}$. The same behaviour is shown for separation of $2.2 \mathrm{~mm}$, but for the intermediate separation of $2.4 \mathrm{~mm}$, the flow is also un-choked but retains a higher degree of symmetry than for the 2.2 and $3.0 \mathrm{~mm}$ separation cases.

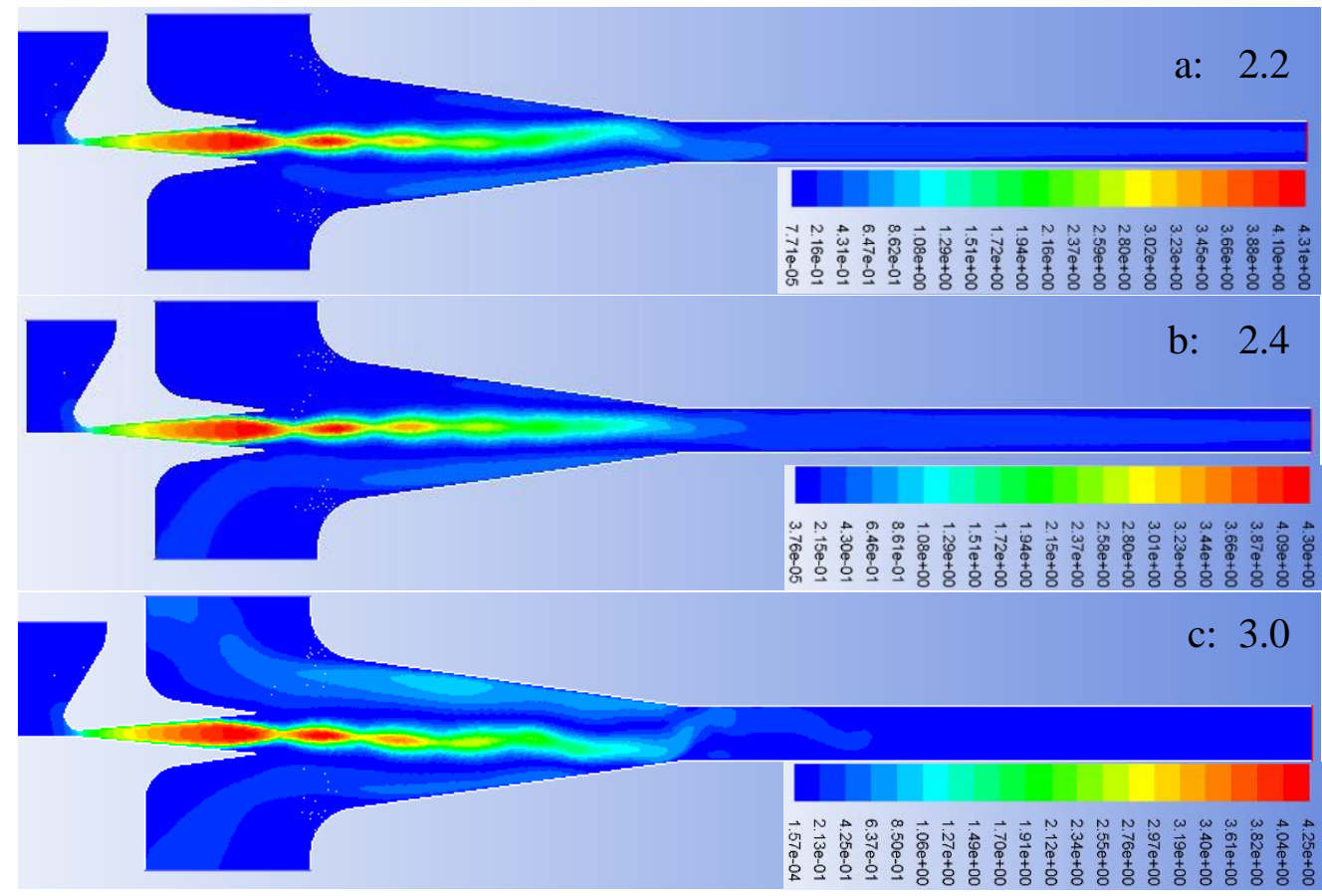

Fig. 6: Contours of Mach number for a: $2.2 \mathrm{~mm}, \mathrm{~b}: 2.4 \mathrm{~mm}$ and c: $3 \mathrm{~mm}$ at primary pressure of $160 \mathrm{kPa}$, secondary pressure of $1.8 \mathrm{kPa}$ and exit pressure of $4.5 \mathrm{kPa}$.

To find the effect of primary pressure on the radial ejector with different separations, higher primary pressures of 200 and $250 \mathrm{kPa}$ were analysed by CFD model. Fig. 7 shows the radial ejector entrainment ratios for primary pressures of 200 and $250 \mathrm{kPa}$. It can be seen that, similar to primary pressure of $160 \mathrm{kPa}$ shown in Fig. 5, by increasing the ejector duct separation, the entrainment ratio increases. These results show that at the low primary pressure of $160 \mathrm{kPa}$, increasing the separation has largest effects on the entrainment ratios. At this working condition, by increasing separation from 2.2 to 3 
$\mathrm{mm}$, the entrainment ratio increases about $34 \%$ while at both higher primary pressures of 200 and $250 \mathrm{kPa}$ the entrainment ratio increase is about $29 \%$. The effects of ejector duct separation on the malfunction pressure is mainly dominant at higher pressures. While the malfunction pressers raise of less than $10 \%$ obtained in primary pressures of 160 and $200 \mathrm{kPa}$, the maximum malfunction raise of more than $15 \%$ obtained for increasing separation from 2.2 to $3 \mathrm{~mm}$ where the primary pressure set at $250 \mathrm{kPa}$.

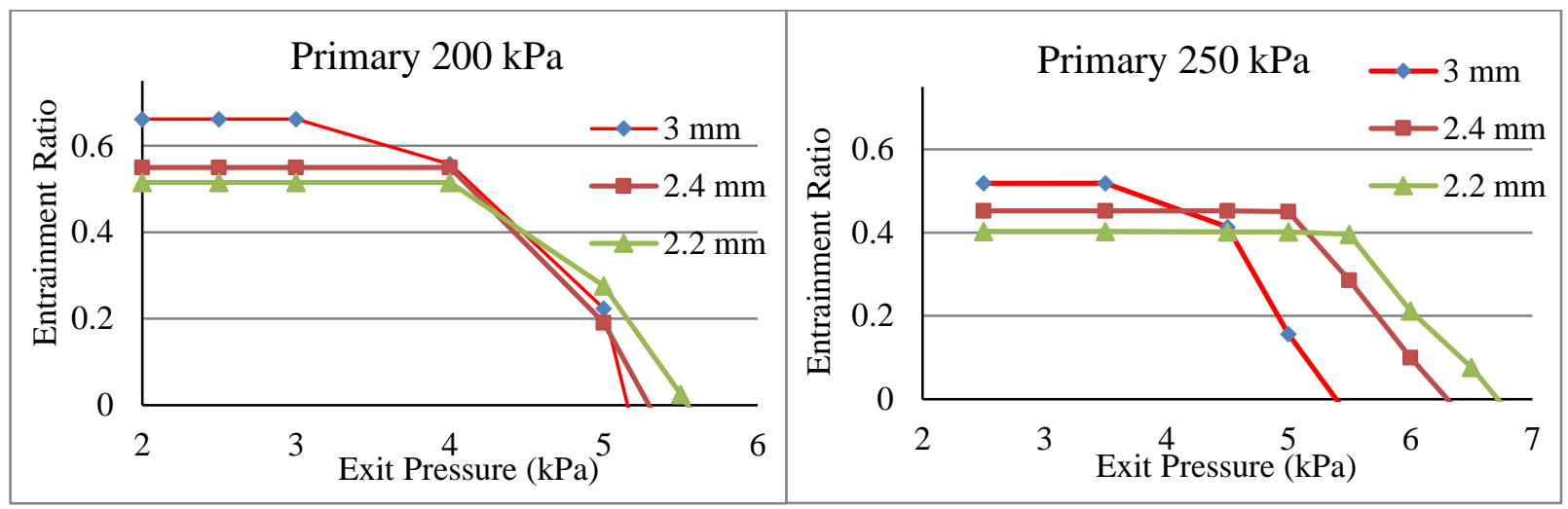

Fig. 7: Characteristic curves for separations of 2.2, 2.4 and $3 \mathrm{~mm}$ for primary pressures of 200 and $250 \mathrm{kPa}$ and the secondary pressure fixed at $1.8 \mathrm{kPa}$.

Fig. 8 shows the static wall pressure along the ejector for separations of 2.2, 2.4 and $3 \mathrm{~mm}$ for primary and secondary pressures of 160 and $1.8 \mathrm{kPa}$ respectively and back pressures of 2.5 and $4.0 \mathrm{kPa}$. The overall trend of the static pressure distribution is similar to what reported by [11]. At low primary pressure of $160 \mathrm{kPa}$, by increasing the ejector duct separation, the static wall pressure along the ejector decrease significantly. It seems by increasing the back pressure to 4 $\mathrm{kPa}$, both ejectors with separations of 2.2 and 2.4 experience very high pressure in the mixing section while the ejector with separation of $3 \mathrm{~mm}$ experiences a much lower static wall pressure along the ejector.

Fig. 9 shows the static wall pressure along the ejector for separations of 2.2, 2.4 and $3 \mathrm{~mm}$ for primary and secondary pressures of 160 and $1.8 \mathrm{kPa}$ respectively and back pressures of 3.5 and $5.5 \mathrm{kPa}$. By increasing the primary pressure to 250 $\mathrm{kPa}$ and with low exit pressure of $3.5 \mathrm{kPa}$, almost a similar trend that exist for primary pressure of $160 \mathrm{kPa}$, experienced in the mixing section of the ejector. However, around the ejector throat and in diffuser section, the trend is changed. By increasing the ejector wall separation at this working condition, the wall pressure of diffuser raises. At high back pressure of $5.5 \mathrm{kPa}$, increasing the ejector duct separation leads to increase in ejector static wall pressure along the ejector. By increasing the back pressure in all separations, the position of the compression moves upstream.

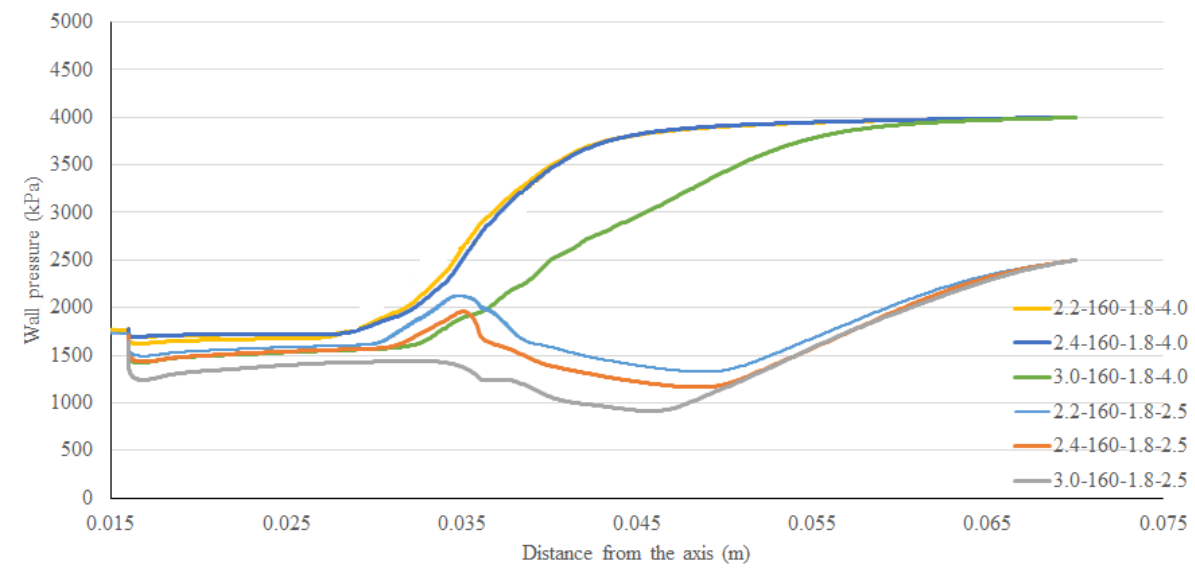

Fig. 8: Static wall pressure for primary pressure of $160 \mathrm{kPa}$ and exit pressures of 2.5 and $4 \mathrm{kPa}$. 


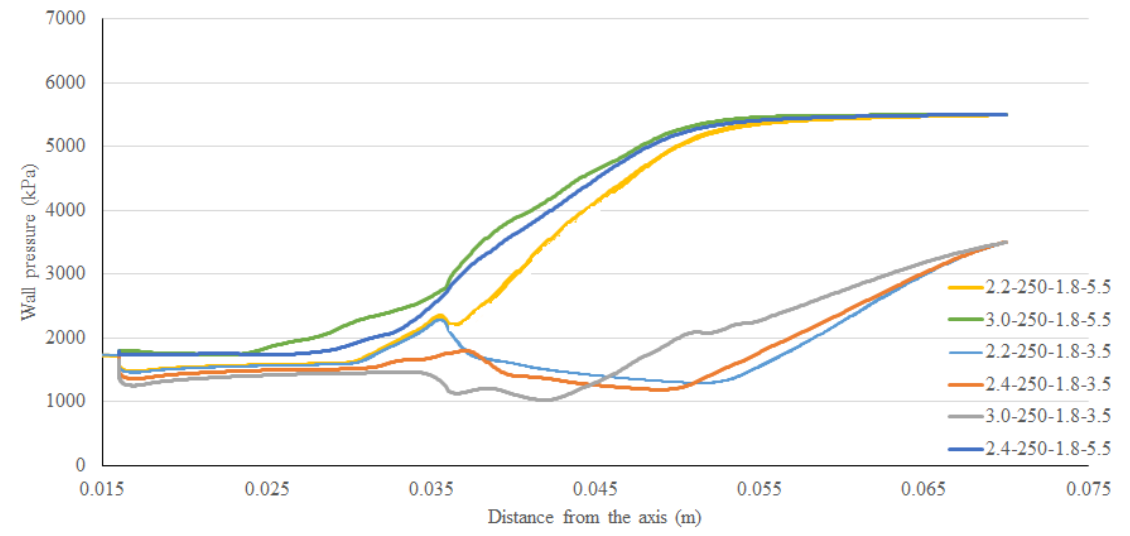

Fig. 9: Static wall pressure for primary pressure of $250 \mathrm{kPa}$ and exit pressures of 3.5 and $5.5 \mathrm{kPa}$

\section{Conclusion}

CFD simulations using ANSYS-FLUENT has been performed for a variable flow geometry supersonic radial ejector configuration working with air. Three different ejector flow areas created by increasing the separation of the radial ejector ducts from $2.2 \mathrm{~mm}$ to $2.4 \mathrm{~mm}$ and $3 \mathrm{~mm}$. The CFD results reveal that by simply changing the separation of ejector ducts, different ejector performance in terms of entrainment ratio and malfunction pressure could be achieved.

It can be concluded that at certain working conditions, obtaining higher entrainment ratios could be achieved by increasing the radial ejector separation. In the current configuration, an entrainment ratio increase of $34 \%$ was achieved by increasing the ejector duct separation from $2.2 \mathrm{~mm}$ to $3 \mathrm{~mm}$. increasing the separation sacrificing the maximum achievable malfunction pressure. By decreasing the ejector duct separation from $3 \mathrm{~mm}$ to $2.2 \mathrm{~mm}$, a maximum increase of about $18 \%$ was achieved in some working conditions.

Results from the CFD simulations show that variable area ejector is applicable and can be simply achieved by radial ejector configuration. To progress the variable radial ejector concept towards a physical solution, experiments on an experimental configuration with ability to change during the operation are required. Further simulations using validation data from such a prototype would also be warranted in order to confidently use the CFD as a design and optimisation tool for the radial configuration.

\section{References}

[1] X. Chen, S. Omer, M. Worall and S. Riffat, "Recent developements in ejector refrigeration technologies," Renewable and Sustainable Energy Reviews, vol. 19, pp. 629-651, 2013.

[2] S. He, Y. Li and R. Z. Wang, "Progress of mathematical modeling on ejectors," Renewable and Sustainable Energy Reviews, vol. 13, pp. 1760-1780, 2009.

[3] N. Ruangtrakoon, S. Aphornratana and M. Sriveerakul, "Experimental studies of a steam jet refrigeration cycle; Effect of the pripary nozzle geometries to system performance," Experimental Thermal and Fluid Science, vol. 35, pp. 676-683, 2011.

[4] S. Varga, A. C. Oliveira, X. Ma, S. A. Omer, W. Zhang and S. B. Riffat, "Experimental and numerical analysis of a variable area ratio steam ejector," International Journal of Refrigeration, vol. 34, pp. 1668-1675, 2011.

[5] S. Varga, P. M. S. Lebre and A. C. Oliveire, "CFD study of a variable area ratio ejector using R600a and R152a refrigerants," International Journal of Referigeration, vol. 36, pp. 157-165, 2013.

[6] V. Dvorak and P. Dancova, "An investigarion into air ejector with pulsating primary flow," World Academy of Science, Engineering and Technology, vol. 5, pp. 542-548, 2011.

[7] D. E. Paxson, J. Eilson and T. Dougherty, "Unsteady Ejector Performance: An experimental investigation using a pulse driver," in Proceedings of $38^{\text {th }}$ AIAA/ASME/SAF/ASFF Joint Propulsion Meeting and Exhibit, Indianapolis, 2002.

[8] K. M. Tacina, "Thrust augmentation in an unsteady supersonic ejector," in Proceedings of 42 ${ }^{\text {nd }}$ AIAA Aeorospace Siences Meeting and Exhibit AIAA, Nevada, 2004. 
[9] A. K. Ababneh, C. A. Garris, A. W. Jawarneh and Tlila, "Investigation of the Mach number effects on fluid-to-fluid interaction in an unsteady ejector with a radial-flow diffuser," Jordan Journal of Mechanical and Industrial Engineering, vol. 3, no. 2, pp. 131-140, 2009.

[10] A. K. Ababneh, A. M. Jayarneh, H. M. Tlilan and Ababn, "The effects of the secondary fluid temperature on the energy transfer in an unsteady ejector with a radial-flow diffuser," Heat Mass Transfer, vol. 46, pp. 95-105, 2009.

[11] H. Rahimi, R. Malpress and D. Buttsworth, "Investigation of Radial Flow Ejector Concept through CFD Analysis," in Proceedings of $20^{\text {th }}$ Australasian Fluid Mechanics Conference, Perth, 2016.

[12] H. D. Kim, J. H. Lee, T. Setoguchi and S. Matsuo, "Computational Analysis of a variable ejector flow," J. of Thermal Science, vol. 15, no. 2, pp. 140-144, 2006.

[13] A. Hemidi , F. Henry, S. Leclaire, J. m. Seynhaeve and Y. Bartosiewicz, "CFD analysis of a supersonic air ejector. Part I: Experimental validation of single-phase and two phase operation," Applied Thermal Engineering, vol. 29, pp. 1523-1531, 2009.

[14] A. Hemidi, F. Henry, S. Leclaire, J.-M. Seynhaeve and Y. Bartosiewicz, "CFD analysis of a supersonic air ejector. part II: Relation between global operation and local flow features," Applied Thermal Engineering, vol. 29, pp. 29902998, 2009.

[15] E. Rusly, L. Aye, W. W. S. Charters and A. Ooi, "CFD analysis of ejector in a combined ejector cooling system," International Journal of Refrigeration, vol. 28, pp. 1092-1101, 2005.

[16] Y. Zhu, W. Cai, C. Wen and Y. Li, "Numerical investigation of geometry parameters for design of high performance ejectors," Applied Thermal Engineering, vol. 29, pp. 898-905, 2009.

[17] ESDU86030, Ejectors and jet pumps. Design for steam driven flow, London: Engineering sciences data unit, 1986.

[18] G. Fadil Lattif Al-Doori, "Investigation of Refrigeration System Steam Ejector Performance through Experiments and Computational Simulations," University of Southern Queensland, Toowoomba, 2013.

[19] T. Sriveerakul, S. Aphornratana and K. Chunnanond, "Performance prediction of steam ejector using computational fluid dynamics: Part 2. Flow structure of a steam ejector influenced by operating pressures and geometries," International Journal of Thermal Science, vol. 46, pp. 823-833, 2007.

[20] N. Ruangtrakoon, T. Thongtip, S. Aphornratana and T. Sriveerakul, "CFD simulation on the effect of primary nozzle geometries for a steam ejector in refrigeration cycle," International Journal of Thermal Sciences, vol. 63, pp. 133$145,2013$.

[21] K. Ariafar, D. Buttsworth, G. Al-Doori and R. Malpress, "Effect of mixing on the performance of wet steam ejectors," Energy, vol. 93, pp. 2030-2041, 2015.

[22] N. H. Johannesen, Ejector Theory and Experiments, Denmark: Akad. for de Tekniske Vi-denskaber, 1951.

[23] G. Flugel, "The design of jet pumps," Technical report, NACA Technical Memo-randum No. 982, 1939.

[24] D. Chong, M. Hu, W. Chen, J. Wang, J. Liu and J. Yan, "Experimental and numerical analysis of supersonic air ejector," Applied Energy, vol. 130, pp. 679-684, 2014. 